\title{
Employee Engagement as a Factor of Internal Entrepreneurship
}

\author{
Marina Shavrovskaya ${ }^{1, *}$, Oksana Borodina $^{2}$ \\ ${ }^{1}$ Ural State University of Economics, Department of Labour Economics and HR Management, 8 Marta 62, 620144 Yekaterinburg, \\ Russia \\ ${ }^{2}$ Omsk State University of Economics, Department of Labour Economics, Mira 55-a, 644077 Omsk, Russia
}

\begin{abstract}
In recent years, there has been a growing interest in the topic of developing employee engagement both in the scientific community and in business. Managers are beginning to realize that not only the technologies used, but also the personnel who can be involved in work, submit ideas on how to improve it, or, conversely, silently carry out job descriptions, which can help to occupy leading positions. The purpose of this study is to analyze publications on employee engagement from 2017-2021, as well as the subjects of their study and research. The main hypothesis is that scientists are interested in various aspects of staff involvement, but of particular interest is how it is interconnected with the effectiveness of the organization. The results of this review form the basis for further discussion on approaches and tools for developing engagement as a factor of internal entrepreneurship.

Keywords: entrepreneurial competence; employee engagement; organizational effectiveness; intraentrepreneurial behavior; internal entrepreneurship
\end{abstract}

\section{Introduction}

The topic of engagement is actively discussed in scientific circles and in business. So, an employee may like working in an organization, but it is not at all necessary that he will be ready to think about how to improve the organization and what to change in specific business processes. Therefore, engagement is not just job satisfaction, it is related to business performance and focuses on the types of behavior that contribute to achieving business results. So, it is proved in a study by Schneider, et al. that employee engagement significantly predicts the financial performance of an organization [1]. According to the approach of B. Shuck, J. L. Adelson, T. G. Reio Jr. the employee engagement scale consists of three sub-factors (cognitive, emotional and behavioral) and a higher-order factor (employee engagement) [2]. Various questionnaires are used to measure employee engagement, for example:

- Gallup (12 questions in the engagement questionnaire) [3]

- $\quad$ AON Hewitt (24 questions) [4]

- $\quad$ Hay Group (database of 200 questions, you can choose the suggested questions to create your survey) [3].

The authors analyze the relationship between performance measurement, performance management, employee engagement and productivity [5]. Min-Seong Kim, Dong-Woo Koo indicate that involvement in work significantly affects the innovative behavior of employees [6]. There are some studies showing a positive correlation between the intraentrepreneurial behavior of employees, personal resources and involvement in work [7].

HR-managers play an important role in the development of both engagement and internal entrepreneurship [8], it is important that they increase employee engagement and productivity by initiating the inclusion of these indicators in performance studies [9]. Although, of course, it is worth noting that managers should help to develop employee engagement. As a result of the research, Min-Seong Kim, Dong-Woo Koo conclude that the direct supervisor plays a crucial role in encouraging engagement, innovative behavior and productivity [6].

A number of authors investigate the relationship between CSR and engagement, showing that the former contributes to an increase in the latter $[10,11]$.

Thus, the issues of engagement are analyzed from different sides, the authors associate it with the efficiency of the organization and productivity improvement, and one of the important roles in this is played by the development of internal entrepreneurship of employees.

\footnotetext{
* Corresponding author: marina_bel@list.ru
} 


\section{Methodology}

This article provides a bibliographic analysis on the topic of employee engagement and internal entrepreneurship with an emphasis on publications from 2017 to 2021 in two databases: Web of Science and RSCI (eLibrary). During analyzing the publications, the definition of "employee engagement" was used to find its presence in keywords. The semantic analysis took into account the number of citations: RSCI $-5 \leq$ citations $\leq 13$, WoS $-5 \leq$ citations $\leq 25$. The authors also analyzed 30 of the most cited publications on the topic of engagement indexed in the databases WoS (25 publications) and RSCI (5 publications) on the subjects of research.

\section{Results and Discussion}

In total, 405 scientific publications have been published on the topic of employee engagement in the RSCI, 296 publications (59\%) and 13 publications of them with a citation $\leq 5$ have been published since 2017 . There are 1256 publications on the topic of employee engagement in the WoS database, 874 (70\%) during the study period.

Figure 1 shows a semantic analysis of publication keywords based on 13 publications of the RSCI $(5 \leq$ citations $\leq 13)$ and 50 publications of the WoS database $(5 \leq$ citations $\leq 25)$.

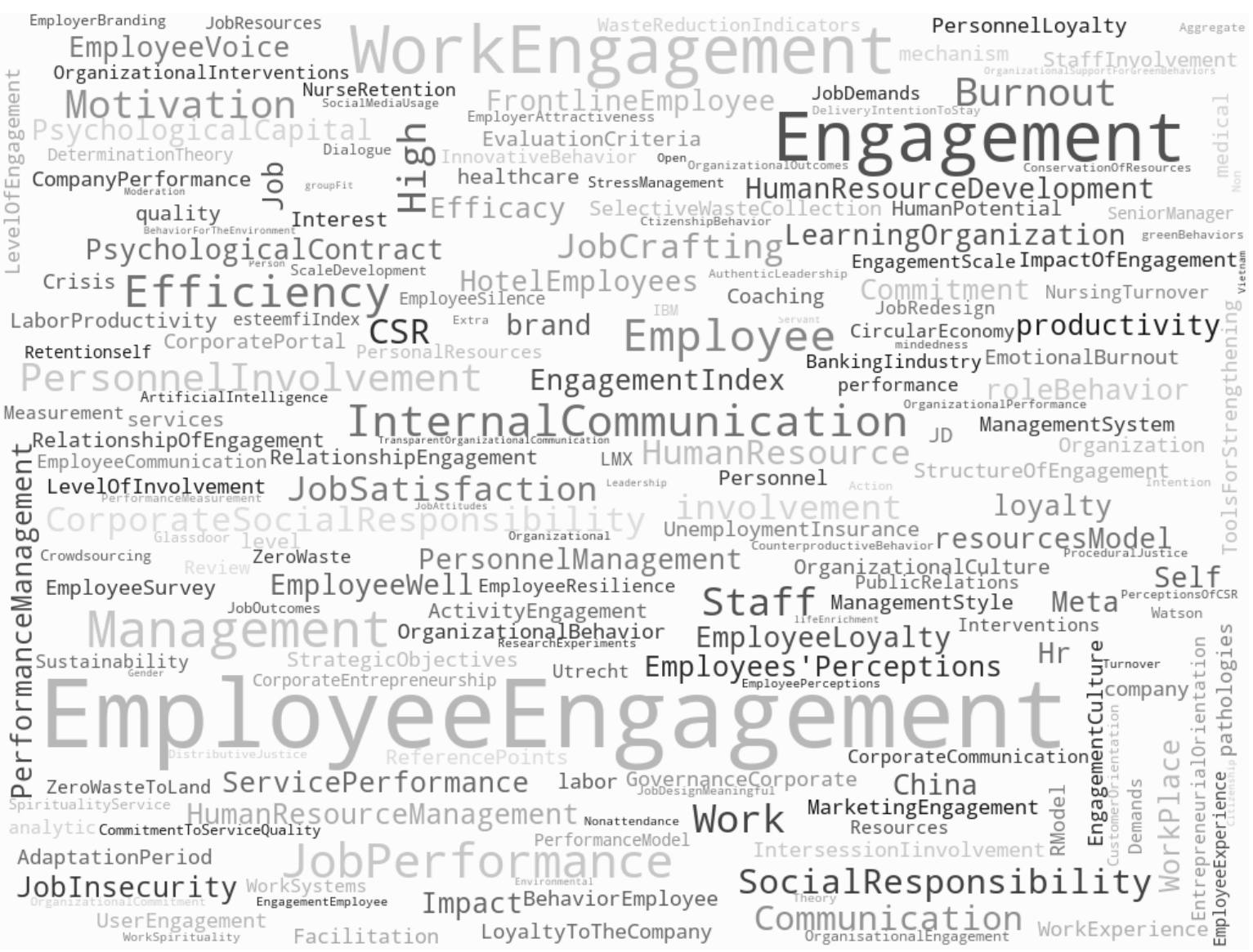

Figure 1. Word cloud of publication keywords on the topic of employee engagement

Source: Author.

It can be seen in Fig. 1 of the word cloud, there are not only synonyms of the concept of " engagement " such as loyalty, commitment, involvement, interest, efficiency, but also antonyms — detachment, indifference, burnout. This indicates the study of this concept from different sides, namely, researchers are looking for answers to such questions: how to analyze the level of engagement, how to involve staff in business processes, how to maintain the achieved level of involvement and thereby develop the company.

In addition, the frequent use of keywords (in addition to the search words "employee engagement") such as efficiency (productivity), communication, social responsibility, motivation and burnout, allow us to say that engagement has two aspects:

- basic competencies (personal characteristics) of employees which influence interest in their profession, passion for the process of activity, the desire to find meaning and pleasure from their work, involvement, initiative and personal interest (not only material) and responsibility for the results of their division and the company as a whole; 
- $\quad$ what the company offers to the employee: a corporate culture aimed at a friendly atmosphere, top management that enjoys respect and trust, various tools that support initiative, and working conditions that affect job satisfaction.

Thus, two types of involvement can be distinguished:

1. Involvement in work - love for the work

2. Involvement in the company - association of oneself with the company

When a person loves what he does, but at the same time does not associate himself with the organization, sometimes it can bring good results. And if teamwork is important, this option can give a negative result.

Table 1 shows the distribution of the 30 most cited publications on the topic of engagement indexed in the WoS (25 publications) and RSCI (5 publications) databases by the subjects of research.

Table 1. The subject of research in 30 most cited publications on the topic of employee engagement

\begin{tabular}{|c|c|c|c|}
\hline Subject of research & $\begin{array}{c}\text { Total } \\
\text { works }\end{array}$ & $\begin{array}{l}\text { Average number of } \\
\text { citations }\end{array}$ & Most cited publications \\
\hline $\begin{array}{l}\text { Research in the } \\
\text { relationship of } \\
\text { engagement with } \\
\text { labor productivity } \\
\text { and efficiency }\end{array}$ & 7 & 60,6 & $\begin{array}{l}\text { B. Smith, } 2017 \text { [5] } \\
\text { Min-Seong Koo, et al, } 2017 \text { [6] } \\
\text { V. Wingerden, et al, } 2017 \text { [12] } \\
\text { Fang Lee Cooke, et al, 2019 [13] } \\
\text { H. Gordon, et al, 2018 [14] } \\
\text { N. V. Gromova, 2018 [15] } \\
\text { G. Reijseger, et al, } 2017 \text { [16] }\end{array}$ \\
\hline $\begin{array}{l}\text { Engagement } \\
\text { research in } \\
\text { particular } \\
\text { companies }\end{array}$ & 6 & 19,7 & $\begin{array}{l}\text { I. V. Rozdolskaya, et al, } 2018 \text { [17] } \\
\text { Z. V. Yakimova, et al, 2018 [18] } \\
\text { U. S. Borisova, } 2017 \text { [19] } \\
\text { J. Milliman, et al, } 2018 \text { [20] } \\
\text { Z. Xin, et al, 2019 [21] } \\
\text { J. Meijerink, et al, 2020 [22] }\end{array}$ \\
\hline Communication & 6 & 44,5 & $\begin{array}{l}\text { K. Minjeong, et al, } 2017 \text { [23] } \\
\text { K. Ruck, et al, } 2017 \text { [24] } \\
\text { O. M. Karatepe, et al, 2018 [25] } \\
\text { P. Holland, et al, 2016 [26] } \\
\text { A. Ivanova, 2018 [27] } \\
\text { J. A. Walden, et al, 2017 [28] }\end{array}$ \\
\hline $\begin{array}{l}\text { Others (burnout, } \\
\text { well-being, CSR, } \\
\text { engagement } \\
\text { measurement, zero } \\
\text { waste and } \\
\text { engagement) }\end{array}$ & 11 & 64,6 & $\begin{array}{l}\text { B. Shuck, } 2018 \text { [2] } \\
\text { J. S. Gawke, et al, } 2017 \text { [7] } \\
\text { V. Veleva, et al, 2017 [29] } \\
\text { M. Willoughby, et al, 2017 [30] } \\
\text { O. M. Karatepe, et al, } 2020 \text { [31] } \\
\text { W. B. Schaufeli, et al, 2017 [32] } \\
\text { C. Flammer et al, } 2017 \text { [10] } \\
\text { T. Farid, et al, 2019 [33] } \\
\text { G. Duthler, et al, } 2018 \text { [11] } \\
\text { T. Lesener, et al, } 2019 \text { [34] } \\
\text { R. Chaudhary, 2017 [35] }\end{array}$ \\
\hline
\end{tabular}

Source: Author.

7 articles out of 30 are devoted to the study of the relationship between engagement and work efficiency or organization, as well as labor productivity. The average number of citations of articles is 60.6 , which indicates an interest in this topic in the scientific community. These issues, one way or another, are related to internal entrepreneurship, the level of which determines the ability to offer and generate ideas for improving existing business processes, as well as creating new products and services, which, in turn, contribute to efficiency growth. In the RSCI database, articles are mainly devoted to the study of employee engagement in a particular organization and the number of citations is quite small. A number of scientists study the relationship between engagement and internal communication (6 articles out of 30 with an average number of citations of 44.5). In addition, the authors are interested in the relationship between engagement and the well-being of staff, CSR, as well as the measurement of engagement and how to involve employees in "zero waste".

During the analysis of the research, the authors identified a number of interesting discussion points that are important for understanding engagement. For example, there is an opinion that employee engagement is a tool to improve the efficiency of the company [36], which is actively used in many organizations. And there is a position, and it is close to the authors, that employee engagement is a management philosophy that forms a culture of participation and helps to involve employees in continuous improvement and increases their personal interest in the success of the organization [17]. It is noteworthy that despite the fact that the formation of a corporate culture that promotes employee engagement is a complex and lengthy process, the approaches in the tools differ significantly. 
Employee engagement should not be viewed through the prism of ideology, as passion. Enthusiasm is easier to create than engagement, but working with emotions gives a short-term effect. True engagement is formed at the expense of values, not agitation, and provides the company with a long-term competitive advantage. Among the recommendations for increasing staff engagement, the following can be highlighted:

- $\quad$ hire already involved candidates with "burning eyes"

- $\quad$ set specific goals for employees that correlate with the success of the organization

- $\quad$ be generous not only with bonuses, but also with praise

- $\quad$ form, first of all, the involvement of managers who, by their example, will involve others in the company's business processes

- $\quad$ form positive emotions and communication in the team

- develop employees, give them the opportunity to feel their importance to the company.

It is worth noting that when measuring employee engagement, it is important to remember that despite the fact that companies strive to increase engagement rates, too high results may be based on negative factors, reflecting "social desirability". In other words, employees may answer questions under pressure or out of fear that they will let down the manager or the service. Taken into account this fact, it is necessary to carefully interpret the data from the engagement surveys.

\section{Conclusion}

The involvement of personnel in the work is the most important condition for the effective functioning of organizations of various types. The statement that a highly qualified specialist is the most valuable asset of the organization is beyond doubt. However, the effectiveness of an employee's work depends on many factors: his interest in working effectively, awareness of his value in the organization, the degree of satisfaction with the content of work, the corporate culture, prospects for personal and professional growth, the availability of working conditions and many other factors. Therefore, increasing the involvement of personnel in the work of the organization becomes the most important task of managers and the company as a whole. The high speed of technology change, the increase in the volume of information, the need for people (especially, the youth) to realize in existing conditions, as well as the need for opportunities to implement their ideas, requires the use of new approaches to human resource management.

The authors analyzed publications on employee engagement for the period of 2017-2021, as well as the topics of their study and research. We have confirmed the hypothesis that scientists are interested in various aspects of staff involvement, e.g. communication, social responsibility, motivation and burnout. The authors research how employee engagement is interrelated to the effectiveness of the organization. The probability that an involved employee will submit more ideas to improve business processes and become an internal entrepreneur is higher than an uninvolved one. But there are a number of issues that still need to be analyzed further, for example, whether it is possible to immediately accept involved employees, and how to form a culture that will support this involvement, or how to direct managers to work in this direction.

\section{References}

1. B. Schneider, A. B. Yost, A. Kropp, C. Kind, H. Lam. Workforce engagement: What it is, what drives it, and why it matters for organizational performance. Journal of Organizational Behavior. 39(4), $462-480$ (2018)

2. B. Shuck, J. L. Adelson, T. G. Reio Jr. The employee engagement scale: Initial evidence for construct validity and implications for theory and practice. Human Resource Management. 56(6), 953-977 (2017)

3. A. A. Tokareva, S. G. Baronene. Methodology of research on the involvement of university employees. University Management: Practice and analysis. 23, 1-2 (2019)

4. A. Hewitt. Trends in Global Employee Engagement[online]. Available at: https://www.business.com/images/content/58a/d9f712f87b1207f720dee/0-0-/ (2012)

5. M. Smith, U. S. Bititci. Interplay between performance measurement and management, employee engagement and performance. International Journal of Operations \& Production Management. 37(9), 1207-1228 (2017)

6. M.-S. Kim, D.-W. Koo. Linking LMX, engagement, innovative behavior, and job performance in hotel employees. International Journal of Contemporary Hospitality Management. 29(12), 3044-3062 (2017)

7. J. S. Gawke, M. J. Gorgievski, A. B. Bakker. Employee entrepreneurship and work engagement: A latent change score approach. Journal of Vocational Behavior. 100, 88-100 (2017) 
8. A. Pesha, M. Shavrovskaya, O. Borodina. Development of Entrepreneurial Competencies of Employees within the Framework of internal Entrepreneurship Programs in the Region. SHS Web of Conferences. 90 (2021)

9. W. R. Carter, P. L. Nesbit, R. J. Badham, S. K. Parker, L.-K. Sung. The effects of employee engagement and selfefficacy on job performance: a longitudinal field study. The International Journal of Human Resource Management. 29(17), 2483-2502 (2018)

10. C. Flammer, L. Jiao. Corporate social responsibility as an employee governance tool: Evidence from a quasiexperiment. Strategic Management Journal. 38(2), 163-183 (2017)

11. G. Duthler, G. S. Dhanesh. The role of corporate social responsibility (CSR) and internal CSR communication in predicting employee engagement: Perspectives from the United Arab Emirates (UAE). Public relations review. 44(4), 453-462 (2018)

12. J. V. Wingerden, D. Derks, A. B. Bakker. The impact of personal resources and job crafting interventions on work engagement and performance. Human Resource Management. 56(1), 51-67 (2017)

13. F. L. Cooke, B. Cooper, T. Bartram, J. Wang, X. Mei. Mapping the relationships between high-performance work systems, employee resilience and engagement: A study of the banking industry in China. The International Journal of Human Resource Management. 30(8), 1239-1260 (2019)

14. H. J. Gordon, E. Demerouti, P. M. Le Blanc, A. B. Bakker, T. Bipp, M. A. M. T. Verhagen. Individual job redesign: Job crafting interventions in healthcare. Journal of Vocational Behavior. 104 (2018)

15. N. V. Gromova. Employee engagement is the main reserve for improving the efficiency of modern companies. Bulletin of the Russian University of Economics. G. V. Plekhanov. 6 (2018)

16. G. Reijseger, M. C. W. Peeters, T. W. Taris, W. B Schaufeli. From motivation to activation: why engaged workers are better performers. Journal of Business and Psychology. 32(2), 117-130 (2017)

17. I. V. Rozdolskaya, M. E. Ledovskaya, Y. A. Mozgovaya. Creating a culture of engagement as a method of motivating staff in the process of implementing the strategic goals of the organization. Bulletin of the Belgorod University of Cooperation, Economics and Law. 5 (2018)

18. Z. V. Yakimova, A. S. Pushkin. Dynamics of the level of staff involvement depending on the length of service in the organization. Azimuth of scientific research: Economics and Management. 22 (2018)

19. U. S. Borisova, L. N. Vasilyeva. Involvement of the organization's personnel: a sociological analysis. Society: sociology, psychology, pedagogy. 5 (2017)

20. J. Milliman, A. Gatling, J. Kim. The effect of workplace spirituality on hospitality employee engagement, intention to stay, and service delivery. Journal of Hospitality and Tourism Management. 35, 56-65 (2018)

21. Z. Xin, M. Liang, X. Feng, X. Bo. How social media usage affects employees' job satisfaction and turnover intention: An empirical study in China. Information \& Management. 56(6) (2019)

22. J. Meijerink, A. Bos-Nehles, J. de Leede. How employees' pro-activity translates high-commitment HRM systems into work engagement: The mediating role of job crafting. The International Journal of Human Resource Management, 31(22), 2893-2918 (2020)

23. K. Minjeong, S. Minjung. How symmetrical employee communication leads to employee engagement and positive employee communication behaviors: The mediation of employee-organization relationships. Journal of Communication Management. 21(1), 82-102 (2017)

24. K. Ruck, M. Welch, B. Menara. Employee voice: an antecedent to organizational engagement? Public Relations Review. 43(5), 904-914 (2017)

25. O. M. Karatepe, A. Ozturk, T. T. Kim. The effects of organizational and personal resources on stress, engagement, and job outcomes. International Journal of Hospitality Management. 37(4), 858-879 (2018)

26. P. Holland, B. Cooper, C. Sheehan. Employee voice, supervisor support, and engagement: The mediating role of trust. Human Resource Management. 56(6) (2016)

27. A. Ivanova. Research of Corporate portal resources in Personnel Engagement Management. Human Resources and Intellectual Resources management in Russia. (2018)

28. J. A. Walden, E. H. Jung, C. Y. K. Westerman. Employee communication, job engagement, and organizational commitment: A study of members of the Millennial Generation. Journal of Public Relations Research. 29(5), 1-17 (2017)

29. V. Veleva, G. Bodkin, S. Todorova. The need for better measurement and employee engagement to advance a circular economy: Lessons from Biogen's "zero waste" journey. Journal of Cleaner Production. 154, 517-529 (2017) 
30. M. Willoughby, M. Parsons, P. Boxall, G. Cheung. Factors predicting Registered Nurses' intentions to leave their organization and profession: A job demands-resources framework. Journal of advanced nursing. 74(5) (2017)

31. O. M. Karatepe, H. Rezapouraghdam, R. Hassannia. Job insecurity, work engagement and their effects on hotel employees' non-green and nonattendance behaviors. International Journal of Hospitality Management. 87 (2020)

32. W. B. Schaufeli, et al. An Ultra-Short Measure for Work Engagement The UWES-3 Validation Across Five Countries. European Journal of Psychological Assessment (2017)

33. T. Farid, S. Iqbal, S. Castro-González, J. Ma. Employees' perceptions of CSR, work engagement, and organizational citizenship behavior: The mediating effects of organizational justice. International Journal of Environmental Research and Public Health. 16(10), 1731 (2019)

34. T. Lesener, G. Burkhard, C. Wolter. The job demands-resources model: A meta-analytic review of longitudinal studies. Work \& Stress. 33(1), 76-103 (2019)

35. R. Chaudhary. Corporate social responsibility and employee engagement: can CSR help in redressing the engagement gap? Social Responsibility Journal. (2017)

36. S. Marisa, U. S. Bititci. Interplay between performance measurement and management, employee engagement and performance. International Journal of Operations \& Production Management. 37(9), 1207-1228 (2017) 